STUDENTS’ PRIOR TOPIC BELIEFS

Nordic Psychology, 2017

Vol. 69, No. 3, 127-142

The Role of Students' Prior Topic Beliefs in Recall and Evaluation of Information from Texts on Socio-Scientific Issues.

Helge I. Strømsø, Ivar Bråten, and Tonje Stenseth University of Oslo, Norway

Address for correspondence: Helge I. Strøms $\varnothing$, Department of Education, University of Oslo, P.O. Box 1092 Blindern, N-0317 Oslo, Norway

Phone: + 47228581 88, Fax: + 47228542 50, E-mail: h.i.stromso@ @ed.uio.no 


\title{
The Role of Students' Prior Topic Beliefs in Recall and Evaluation of Information from Texts on Socio-Scientific Issues.
}

\begin{abstract}
In this research, we investigated relationships between undergraduate students' prior topic beliefs and their recall of the main conclusions from texts on controversial socio-scientific issues, to what extent students trusted the recalled conclusions, and how they justified their trust in those conclusions. While belief-biased recall of text conclusions was not observed in this study, students were found to trust the recalled conclusions more when they were consistent than when they were inconsistent with students' prior beliefs about the issues. Moreover, students primarily justified their trust in the recalled conclusions by referring to their personal opinions on the issues. Finally, students who correctly recalled text conclusions even when those conclusions were at odds with their prior beliefs about the issues outperformed students who incorrectly recalled conclusions that were consistent with their prior beliefs on measures of cognitive reflection and reported use of critical reading strategies. Theoretical as well as educational implications of these findings are discussed.
\end{abstract}

Keywords: Beliefs; Text; Recall; Evaluation; Social-scientific issues. 


\section{Introduction}

Scientific issues with social ramifications, such as climate change and advances in medical treatment, receive considerable public attention. Citizens of democratic societies are constantly presented with such socio-scientific issues and there are concerns that people in general are not able or willing to deal with information at odds with what they already believe to be true (Nisbet \& Mooney, 2007). Such concerns are related to how people deal with important decisions in daily life, for example regarding participation in vaccination programs, as well as to how students deal with new information in educational settings. Accordingly, questions regarding biased information processing have been of interest to researchers within social cognition (e.g., Petty \& Wegener, 1999) and educational psychology (e.g., Chinn \& Brewer, 1993). In the present study, we draw on relevant theory and research from both these areas.

Beliefs reflect what individuals accept as or want to be true regardless of verification (Murphy \& Mason, 2006). Beliefs may constitute comprehensive systems, such as religious beliefs, or concern more specific topics, such as global warming, and they are considered to come into play when issues are controversial in the sense that alternative perspectives exist or compete (Abelson, 1979). Also, beliefs may prime or guide individuals' reading goals and processing activities and what they take away from reading (Bråten, Ferguson, Strøms $\varnothing, \&$ Anmarkrud, 2013; Murphy \& Mason, 2006). In this study, we focused on students' beliefs about two socio-scientific issues that have been controversially discussed for several years and are of great concern to the general public: whether consumption of the artificial sweetener aspartame and use of cell phones, respectively, represent any serious health risks. We had students in higher education read about the issues in popular science texts and examined their 
memory for and trust in claims set forth in the texts when the claims were inconsistent versus consistent with their prior beliefs, as well as how they justified their trust in the claims that they actually recalled. Additionally, we investigated whether students' cognitive reflection and their self-reported critical evaluation of information in popular media were related to their recall of the textual claims that they read.

\subsection{Prior beliefs and recall}

It has long been acknowledged that readers' initial perspective may affect what information they take away from a text. For example, in a seminal study, Pichert and Anderson (1977) observed that readers assigned the perspective of a homebuyer recalled different information from a text describing a house than did those assigned the perspective of a burglar. Thus, perspective-consistent information was more easily stored in memory during reading and more accessible for later recall. Later, Woll and Graesser (1982) proposed that information inconsistent with readers' expectations would be encoded with a unique "tag" in the memory representation of a text. This view (termed "the schema-pointer plus tag model") thus predicts that both expectancy-consistent and expectancy-inconsistent information may be encoded and later recalled.

In a meta-analysis including studies of how social expectations may influence people's recall of expectancy-consistent and expectancy-inconsistent information about persons or groups, Stangor and McMillan (1992) found a tendency towards better recall of expectancyinconsistent information. This tendency was, however, moderated by a number of variables, with expectancy-consistent information seemingly better recalled when people held strong beliefs, when new information was hard to process, and when recall was hampered by a time delay. While Stangor and McMillan's (1992) review included only studies of stereotypical 
beliefs, Roberts (1985) conducted a meta-analysis omitting research on stereotypes and including only studies focusing on the selective recall hypothesis, predicting superior recall of information consistent with the attitudes a person holds. Results from that meta-analysis showed only a modest relationship between attitudes and recall, however, with studies using delayed recall tests demonstrating the clearest relationship. A delayed recall test implies that the reader has to reconstruct information from long-term memory, and those reconstruction processes may depend more heavily on established beliefs than on text content. Taken together, the two cited meta-analyses (Roberts, 1985; Stangor \& McMillan, 1992) indicate that prior beliefs may affect people's recall of what they have read in different ways, but that such effects may be moderated by variables related to the person as well as the task. Later, several studies have confirmed that there does not seem to be a clear-cut relationship between people's prior beliefs and what they recall from texts (e.g., Maier \& Richter, 2013; Wiley, 2005). In essence, studies of the relationship between prior beliefs and recall are concerned with the extent to which, and under what circumstances, readers are able to recall arguments that are inconsistent with what they believe to be true. However, even when they are able to do this, an equally important question arises: to what extent will they trust such beliefinconsistent information?

\subsection{Prior beliefs and trust in new information}

Numerous studies have shown that information is more likely to be accepted by people when it is consistent with what they already believe to be true, indicating that people tend to evaluate information consistent with prior beliefs more positively than information inconsistent with prior beliefs (e.g., Kardash \& Scholes, 1996; Lord, Ross, \& Lepper, 1979; Murphy \& Alexander, 2004; Taber \& Lodge, 2006). That belief-consistent information tends 
to be judged more favorably than belief-inconsistent information may be explained by theories concerning the need for cognitive consistency (Gawronski \& Strack, 2012) and motivated reasoning (Molden \& Higgins, 2005). Cognitive consistency theory predicts that belief-inconsistent information often will be evaluated negatively because people otherwise might have to reconsider a number of interlinked beliefs, which would require more effort and motivation. Motivated reasoning theories emphasize people's motives for positive selfevaluation and argue that belief inconsistency may elicit negative feelings (Molden \& Higgins, 2005). However, whether inconsistency triggers a cognitive process aimed at restoring consistency will probably depend on how important a person's initial beliefs are to that person (Kahan et al., 2012) and the relevance of the new information (Kruglanski \& Shteynberg, 2012).

Whether new information is consistent with prior beliefs or not may also have implications for the way it is processed. Dual processing models of cognition (e.g., Petty \& Wegener, 1999) assume two routes of information processing varying in terms of depth. When presented with belief-inconsistent information, individuals may engage in extensive and effortful information processing in an attempt to refute or undermine that information. In contrast, when individuals read belief-consistent information, they may process that information in a more shallow way by relying on prior beliefs and heuristics that require little cognitive effort (Andiliou, Ramsay, Murphy, \& Fast, 2012; Klaczynski, Gordon, \& Fauth, 1997; Molden \& Higgins, 2005). Although individuals, thus, may engage both routes of information processing in order to retain prior beliefs, the more deep and effortful route seems to increase the possibility of belief change (Andiliou et al., 2012). Such belief change seems to require that readers are able to separate their prior beliefs from the reasoning process, however (Stanovich, West, \& Toplak, 2013). That is, they must be able to suppress their 
intuitive opinion regarding the issue in order to reflect on and evaluate the arguments presented.

In summary, current evidence suggests that students seldom change their prior beliefs from reading about issues that in some way matters to them, with their processing of beliefinconsistent information tending to leave their prior beliefs intact or even strengthening them. Moreover, several studies report on how students justify their trust in messages conveyed by texts, demonstrating that undergraduates at relatively low levels of domain expertise primarily give content reasons for their trustworthiness judgments (Bråten, Strøms $\varnothing, \&$ Salmerón, 2011; Rouet, Britt, Mason, \& Perfetti, 1996; Wiley et al., 2009). In contrast, trustworthiness judgments referring to source features such as author, document type, and publisher, or to the readers' own opinion, are less emphasized. One should note, however, that participants in studies cited above were given a cued justification task, having access to source information and a short description of the texts' content when asked to justify their evaluations. According to the Elaboration Likelihood Model (Petty \& Wegener, 1999), individuals processing new information in a deep, effortful way will often judge the message based on both content and source information, whereas individuals processing the information in a more shallow way will rely on more peripheral cues, which could be source information or their own opinion on the issue in question. In this view, then, it may be regarded as adaptive that undergraduates tend to emphasize content when judging a text's trustworthiness. Of note is, however, that more knowledgeable readers seem to scrutinize all relevant information, including source information, in order to evaluate a message.

\subsection{The present study}


We investigated relationships between students' prior topic beliefs and their recall of the main conclusions from texts on socio-scientific issues, to what extent students trusted the recalled conclusions, and how they justified their trust in those conclusions. In addition, we examined whether students' reflection on cognitive problems and their inclination to critically evaluate information in popular media were related to their recall of the conclusions. The socioscientific issues concerned possible health risks related to the intake of the artificial sweetener aspartame and cell phone radiation, respectively, with both issues presumably relevant to the participating undergraduates' daily lives. In Norway, $100 \%$ of young people (age 15-35) own a cell phone (Norwegian Post and Telecommunications Authority, 2013). Also, aspartame is an artificial sweetener much used in soft drinks, sweets, dairy products, chewing gum, desserts, and a number of other food products, making behavioral decisions on this issue an potential everyday occurrence for our participants.

Our first research question was: Are students' prior topic beliefs associated with their recall of the main conclusions from the texts? Prior research suggests that belief-consistent information is better recalled than belief-inconsistent information when there is a delay between reading and recall (Roberts, 1985; Stangor \& McMillan, 1992). In the current study, the problem solving task following reading presumably erased the text conclusions from participants' working memory. Thus, we hypothesized that participants would be more likely to recall belief-consistent than belief-inconsistent conclusions.

Our second research question was: What is the relationship between students' prior topic beliefs and their trust in the recalled conclusions? While previous studies concerning students' trust in belief -consistent/inconsistent statements have asked participants to judge presented statements, we asked them to judge the conclusions that they actually recalled. In this way, we addressed the relationship between prior topic beliefs and participants' mental representations of the texts' conclusions. Prior research indicates that students' evaluation of 
new information is biased by their prior beliefs (e.g., Lord et al., 1979, Taber \& Lodge, 2006), and our hypothesis was, accordingly, that participants' would trust the recalled conclusions more when they were consistent than when they were inconsistent with their prior topic beliefs. Perceived knowledge about the issues was included as a covariate because prior knowledge might affect participants' evaluation of the recalled conclusions (Petty \& Wegener, 1999; Wiley, 2005).

Our third research question was: How do participants justify their evaluations of the recalled conclusions? In previous studies, participants had source and brief content information available when justifying their evaluations of trustworthiness (e.g., Bråten et al., 2011; Rouet et al., 1996; Wiley et al., 2009), with those studies showing that students justified their evaluations mostly by referring to text content. Because we did not use a similar, cued justification task, and because we expected our participants to have opinions on the two issues, we hypothesized that participants would generally justify their trust in the conclusions by referring to their own opinions.

Finally, our fourth research question asked: Do participants who hold text-inconsistent beliefs, yet recall text-consistent conclusions, display more cognitive reflection and reportmore use of critical reading strategies than participants who hold text-inconsistent beliefs and also recall text-inconsistent conclusions? Prior research indicates that readers' prior beliefs may affect their information processing, with belief-inconsistent information tending to be processed in a deeper way than belief-consistent information (Kaczynski et al., 1997; Petty \& Wegener, 1999). Accordingly, we expected that recall of text-consistent conclusions at odds with prior beliefs would be associated with higher levels of cognitive reflection and critical reading strategies, which may facilitate deeper-level processing of such belief-inconsistent information. 


\section{Method}

\subsection{Participants}

A total 205 first-year students (47.3\% females) at a university college in south-east Norway volunteered to participate in the study. The students attended five different bachelor-level programs of professional education: teaching $(n=49)$, engineering $(n=37)$, informatics $(n=$ $51)$, nursing $(n=19)$, and economics $(n=48)$. Overall mean age was $23.81(S D=6.37)$. All participants had completed at least 12 years of schooling before starting on professional education.

\subsection{Text materials}

Each participant read one 325-word text on the controversial issue of whether the artificial sweetener aspartame might pose any health risk and one 379-word text on the controversial issue of whether cell phone radiation might have any negative health effects. The two texts were presented on separate sheets of paper. The aspartame text was from a bi-weekly magazine for the health care sector called Today's Medicine; the cell phone text from a popular science magazine called the Illustrated Science. Although both texts acknowledged that there were opposing views on the respective issues, they both clearly concluded that, based on available research-based evidence, there were no health risks.

Both texts had headings indicating that they contained information about possible relationships between artificial sweeteners and cell phones, respectively, and health risks. The text on artificial sweeteners was written by the named editor of the health care magazine, and in addition to this information about the author and the author's credentials, information about 
the publication and the date of creation was provided. The text on cell phone use was written by a named research reporter, with information about the publication and date of publication provided in addition to this information about the author and the author's credentials.

Both texts consisted of four paragraphs including the same type of content across texts. In the first paragraph, the issue was briefly introduced and readers were told that some people think that intake of artificial sweeteners/use of cell phones may cause serious health problems, whereas others think that both are perfectly safe. The second paragraph explained in neutral terms how artificial sweeteners are produced and digested and how cell phones work, respectively. In the third paragraph, it was referred to a recent research review by an expert on the issue in question, providing information about the different types of investigations that were included in the reviews. Finally, the fourth paragraph concluded, based on the expert review, that there was no evidence showing a relationship between the consumption of aspartame/cell phone use and health problems.

\subsection{Measures}

\subsubsection{Topic beliefs}

Participants' prior topic beliefs were assessed with a four-item inventory asking participants to rate their agreement with two statements concerning artificial sweeteners (e.g., "I believe there is a relationship between intake of the artificial sweetener aspartame and health problems") and two items concerning cell phones (e.g., "I do not believe that cell phone radiation can cause cancer" [reverse coded] $)$ on a 10 -point scale $(1=$ not at all true, $10=$ very true). Scores on the measure of prior beliefs concerning artificial sweeteners yielded an 
internal consistency reliability (Cronbach's $\alpha$ ) of .85 ; for scores on the measure of prior beliefs concerning cell phones, the reliability estimate was .92 .

\subsubsection{Self-reported prior knowledge}

As a proxy for prior knowledge, we used three items to assess participants' perceived knowledge of or familiarity with each of the issues discussed in the texts. On all items, participants rated their agreement with the knowledge statements ("I have knowledge about ...”) on a 10-point scale ( $1=$ disagree completely, $10=$ agree completely $)$. Participants' scores showed satisfactory internal consistency reliabilities for both issues, with Cronbach's $\alpha$ $=.88$ for the items concerning artificial sweeteners and .73 for the items concerning cell phones. Please note that prior research has found perceived knowledge to play an important role in students' judgments of new information (Andiliou et al., , 2012).

\subsubsection{Cognitive Reflection Test}

The three-item Cognitive Reflection Test (CRT) (Frederick, 2005) was used to assess participants' general ability to suppress an intuitive and spontaneous wrong answer in favor of a reflective correct answer. The test is composed of three tasks (sample item: "A bat and a ball cost $\$ 1.10$ in total. The bat costs a dollar more than the ball. How much does the ball cost?"). The Cronbach's $\alpha$ for scores on the three-items measure was .59, with this somewhat low level of reliability probably attributable to the fact that particular items were very hard for our participants.

The CRT has also been described as a measure of "the tendency to accept heuristically triggered responses” (Toplak, West, \& Stanovich, 2011, p.1284). In several studies, it has 
been shown to correlate moderately with both cognitive ability and skills in rational thinking, but also to independently predict central aspects of rational thought (Frederick, 2005; Toplak et al., 2011).

\subsubsection{Recall of conclusion}

After having read the texts, participants were asked to write down the main conclusion of each. Their responses were coded 1 when the recalled conclusion was consistent with the conclusion of the text and 0 when the recalled conclusion was inconsistent with the conclusion of the text. A random sample of $23 \%$ of participants' conclusions was independently coded by the first and the second author, resulting in an inter-rater agreement of $96 \%$ (Cohen's $\kappa=.91)$.

\subsubsection{Trust in conclusion}

After having attempted to recall the conclusion of a text, participants were asked to rate the extent to which they trusted the recalled conclusion, using a 5-point scale ranging from not at all (1) to to a very high degree (5).

\subsubsection{Justification of trustworthiness ratings}

For each text, participants were also asked to briefly justify their trustworthiness rating, with their responses coded in five different categories: 1) content (references to idea units in the text), 2) main source (references to the source of the text (e.g., author or venue), 3) embedded source (references to a source cited within a text (e.g., a professor or a research report), 4) 
other source (references to other texts, persons, or previous knowledge about the issue), and 5) personal opinion (references to participants' personal opinion about the issue in question). Each justification was coded 0 or 1 for each category, with justifications indicative of more than one category given a code of 1 for each of those categories. Two independent judges (the first and second authors) used the coding categories described above to score a random selection of $23 \%$ of participants' justifications, resulting in an inter-rater agreement of $93 \%$ (Cohen's $\kappa=.87)$.

\subsubsection{Critical reading of media reports of science}

To assess participants' likelihood of critically evaluating science-related information presented in popular media, we developed the Critical Reading of Media Reports of Science Scale (CROMROSS). Three of the items were adapted from the Critical Thinking subscale of the Motivated Strategies for Learning Questionnaire (MSLQ) (Pintrich, Smith, Garcia, \& McKeachie, 1993), which was designed to measure students' use of strategies to make critical evaluations of ideas by applying previous knowledge to new situations. On the CROMROSS, however, readers were asked to rate their agreement with statements concerning how they relate to information about research and science presented in popular media such as newspapers, magazines, radio, television, or various websites, with all six items included in the scale addressing to what extent readers judge the plausibility of claims through critical thinking (sample item: "When I see claims about new knowledge and new discoveries in the media, I consider how well justified these claims are"). All six items were rated on a 5-point scale $(1=$ very seldom, 5 = very often $)$. The reliability estimate (Cronbach's $\alpha)$ for participants' scores on this measure was 89. 


\subsection{Procedure}

All materials were group administered to the participants in each of the five bachelor programs separately during regular 45-min lectures. The data collection was administrated by the first and second authors together with four trained research assistants. Participation in the project was voluntary and all data were treated anonymously and confidentially.

Each participant received a folder containing all the materials. They answered a questionnaire on demographics before responding to the four topic belief items and the six perceived knowledge items. The two texts were then introduced with the following instruction, written on a separate sheet of paper: "We have copied two articles on current health issues. Read these articles carefully to decide whether you ought to change some of your own habits. When you have finished, you will get some questions about what you read. It is therefore important that you try to remember what you read in these articles." The texts were then presented on separate sheets of paper in counterbalanced order. Participants did not look back to the texts while completing the remaining tasks.

After finishing the texts, participants first worked on the Cognitive Reflection Test (CRT), with this procedure, presumably, erasing the conclusions from participants' working memory. After completing the CRT, participants were asked to state the main conclusion of the text they had read first, rate to what extent they trusted the recalled conclusion, and justify their trustworthiness rating. Participants then completed the same tasks in the same order for the text they had read second.

Finally, participants completed the Critical Reading of Media Reports of Science Scale (CROMROSS). The reason for this was that we intended that participants should process the texts without being cued on the importance of critically evaluating their claims. 


\section{Results}

Table 1 shows descriptive statistics for the measured variables for the entire sample. An alpha level of .05 was used for all subsequent statistical tests.

[Table 1 about here]

Participants were divided into those holding text-consistent and those holding textinconsistent prior topic beliefs on the basis of their scores on the two topic belief measures, with a score of four or lower considered indicative of text-consistent topic beliefs and a score of six or higher considered indicative of text-inconsistent topic beliefs. Please remember that because both texts concluded that there were no health risks, text-consistent beliefs imply that there are no health risks whereas text-inconsistent beliefs imply that there are health risks. Students with scores between four and six were considered to have neutral topic beliefs and were therefore omitted from further analyses. For the aspartame text, $26.5 \%$ of the participants were categorized as having text-consistent topic beliefs, and $73.5 \%$ were categorized as having text-inconsistent beliefs. For the cell phone text, $40.5 \%$ were categorized as having text-consistent beliefs, and 59.5\% were categorized as having textinconsistent beliefs.

Table 2 shows how the participants in the two topic belief groups were distributed across text-consistent and text-inconsistent recall for the two texts. The two chi-square tests that were performed on these data did not indicate any relationship between topic beliefs and recall, neither for the aspartame text, $\chi^{2}(1, n=170)=.10, p=.76$, nor for the cell phone text, $\chi^{2}(1, n=168)=.65, p=.42$.

[Table 2 about here]

Next, we performed a 2 x 2 between-subjects analysis of variance (ANOVA) on each of the measures of trust in the conclusion, that is, trust in the recalled aspartame conclusion 
and trust in the recalled cell phone conclusion, respectively. Independent variables were prior topic beliefs (text consistent vs. text inconsistent) and recall of conclusion (text consistent vs. text inconsistent). Not only scores on the measure of self-reported prior knowledge, but also scores on the cognitive reflection (CRT) and critical reading (CROMCROSS) measures, were regarded as potential covariates in these analyses. Because none of those scores correlated with the dependent measures, however, they were not included in the two ANOVAs that we performed (Field, 2010).

The first ANOVA showed that neither prior topic beliefs $(F(1,162)=.97, p=.325$, partial $\left.\eta^{2}=.006\right)$, nor recall of conclusion $\left(F(1,162)=1.91, p=.169\right.$, partial $\left.\eta^{2}=.012\right)$, had a statistically significant main effect on trust in the recalled aspartame conclusion. However, a statistically significant interaction between prior topic beliefs and recall of conclusion was observed, with $F(1,162)=7.45, p=.007$, partial $\eta^{2}=.044$. The nature of this interaction is displayed in Figure 1. To follow up the interaction, we ran two one-way ANOVAs to examine between-group differences in trust scores. For participants holding text-consistent topic beliefs, there was no statistically significant difference in the trust scores of those recalling text-consistent $(M=3.04, S D=.98)$ and text-inconsistent conclusions $(M=2.80, S D=1.06)$, with $F(1,42)=.62, p=.44, d=.24$. For participants holding text-inconsistent topic beliefs, however, those who recalled text-inconsistent conclusions $(M=3.47, S D=1.10)$ had statistically significantly higher trust in their recalled conclusion than those who recalled textconsistent conclusions $(M=2.73, S D=.95)$, with $F(1,122)=16.66, p<.001, d=.72$. Thus, while participants initially holding beliefs consistent with the text conclusion seemed to trust the recalled conclusion to a similar degree whether it was belief-consistent or beliefinconsistent, participants holding prior topic beliefs inconsistent with the text conclusion seemed to trust the recalled conclusion more when it was belief-consistent than when it was belief-inconsistent. 
[Figure 1 about here]

Results from the second ANOVA, using trust in the recalled cell phone conclusion as the dependent variable, also showed no statistically significant main effect of prior topic beliefs $\left(F(1,160)=.01, p=.906\right.$, partial $\left.\eta^{2}=.000\right)$ or recall of conclusion $(F(1,160)=.27, p=$ .606 , partial $\eta^{2}=.002$ ). However, again a statistically significant interaction between prior topic beliefs and recall of conclusion was observed, with $F(1,160)=40.72, p<.001$, partial $\eta^{2}=.203$. Figure 2 displays the nature of this interaction. The two follow-up one-way ANOVAs that we performed to examine between-group differences in trust scores showed that for participants holding text-consistent topic beliefs, there was a statistically significant difference in trust scores between those recalling text-consistent $(M=3.74, S D=.81)$ and text-inconsistent conclusions $(M=2.54, S D=1.20)$, with $F(1,65)=18.59, p<.001, d=1.19$. For participants holding text-inconsistent topic beliefs, those who recalled text-inconsistent conclusions $(M=3.67, S D=.82)$ had statistically significantly higher trust in the recalled conclusion than those who recalled text-consistent conclusions $(M=2.65, S D=.91)$, with $F(1,94)=23.66, p<.001, d=1.18$. Taken together, then, results were consistent with our expectation that participants would trust the recalled conclusions more when they were consistent than when they were inconsistent with their prior topic beliefs. Importantly, this tendency was apparent even when the conclusions that participants recalled were at odds with what the texts actually said.

[Figure 2 about here]

Table 3 displays frequencies and percentages for the different categories of justifications. Participants mainly (viz. 58.8 and 48.4\%) referred to their personal opinion when justifying their trustworthiness ratings. To some extent, they also referred to textual content (viz. 18.1 and 23.2\%) and other sources (viz. 18.6 and 22.3\%), while there were very few references to main or embedded sources. The two source categories (i.e., main and 
embedded sources) were therefore not included in the loglinear analyses that we performed to examine whether participants justified their trust in the recalled conclusions differently depending on their prior topic beliefs and the nature of the recalled conclusions. Please note that loglinear analysis basically is an extension of the chi-square test that includes three or more categorical variables (Field, 2010). For each of the two texts, we performed three threeway loglinear analyses (justification $\mathrm{x}$ topic beliefs $\mathrm{x}$ recall of conclusion), one for each of the justification categories of personal opinion, content, and other source. The three-way interactions were not statistically significant for the analyses involving justification by personal opinion, with $\chi^{2}(1, n=170)=1.17, p=.28$., for the aspartame text, and $\chi^{2}(1, n=170)$ $=.01, p=.92$, for the cell phone text. Neither for the analyses involving justification by content $\left(\chi^{2}[1, n=170]=3.28, p=.07\right.$, for the aspartame text, and $\chi^{2}[1, n=168]=.03, p=.86$, for the cell phone text), nor for the analyses involving justification by other source $\left(\chi^{2}[1, n=\right.$ $170)=.00, p=.96$, for the aspartame text, and $\chi^{2}[1, n=168]=.13, p=.72$, for the cell phone text) were any statistically significant three-way interactions observed. As expected, then, participants justified their trust in the recalled conclusions mainly by referring to their own opinions regardless of their prior topic beliefs about the issues and whether they recalled the conclusions correctly or not.

[Table 3 about here]

Finally, for participants holding text-inconsistent prior beliefs, we conducted four $t$ tests to compare scores on the cognitive reflection and critical reading measures between those who recalled text-consistent and those who recalled text-inconsistent conclusions. Participants holding text-inconsistent beliefs but, still, recalling text-consistent conclusions from the aspartame text $(M=.34, S D=.35)$ scored statistically significantly higher on the measure of cognitive reflection (CRT) than did participants holding text-inconsistent beliefs and also recalling text-inconsistent conclusions $(M=.18, S D=.22)$, with $t(121)=2.91, p$ 
$=.004, d=.55$. Also on the measure of critical reading (CROMROSS), participants recalling text-consistent conclusions at odds with prior beliefs $(M=3.28, S D=.95)$ scored significantly higher than participants recalling text-inconsistent conclusions in accordance with their prior beliefs $(M=2.77, S D=.75)$, with $t(120)=3.27, p=.001, d=.60$. The same pattern was found for the cell phone text, with participants holding text-inconsistent beliefs yet recalling text-consistent conclusions scoring statistically significantly higher on the CRT $(M=.29, S D$ $=.33)$ as well as on the CROMROSS $(M=3.15, S D=.92)$ than did participants holding textinconsistent beliefs and also recalling text-inconsistent conclusions $(M=.13, S D=.23$, and $M$ $=2.67, S D=.65)$, with $t(97)=2.34, p=.021, d=.57$, for the CRT, and $t(94)=2.45, p=.016$, $d=.61$, for the CROMROSS.

Of note is that for participants holding text-consistent beliefs, scores on the CRT and the CROMROSS did not differ consistently between those recalling text-consistent and textinconsistent conclusions, with only one test showing a reliable difference (for the aspartame text, those who recalled text-consistent conclusions $[M=3.33, S D=.94]$ scored statistically significantly higher on the CROMROSS than did those recalling text-inconsistent conclusions $[M=2.68, S D=.98], t[39]=2.16, p=.037, d=.68])$. Thus, as we expected, higher cognitive reflection and self-reported critical reading were primarily found among participants recalling text-consistent conclusions that were challenging their prior beliefs about the issues.

\section{Discussion}

The current study uniquely contributes to the literature on students' reading and learning about socio-scientific issues by presenting new findings regarding their biased evaluation of recalled claims, their justifications of those evaluations, and associations between memory for 
text-based conclusions at odds with prior beliefs and tendencies towards reflective and critical information processing.

First, the findings confirmed our hypothesis that readers may trust recalled conclusions more when they are consistent than when they are inconsistent with their prior beliefs, with a particularly interesting finding being that readers who recall incorrect conclusions that are consistent with their prior beliefs may have quite strong confidence in those conclusions. While our results are consistent with previous research indicating that people tend to evaluate new information on relevant socio-scientific issues according to their pre-existing beliefs (e.g., Kardash \& Scholes, 1996; Lord et al., 1979; Taber \& Lodge, 2006), it should be noted that the current study extended that work by having participants evaluate statements that they actually recalled from the texts rather than statements presented by a researcher. Thus, although participants correctly recalling text-consistent conclusions at odds with their prior beliefs may have paid more attention to the content of the texts than did other participants, this did not seem to increase their trust in those conclusions. This is consistent with the idea that readers' judgments of belief-inconsistent messages are not solely dependent on the degree to which they attend to and remember those messages; they will also have to monitor and evaluate their own beliefs about the issues in relation to what the texts actually say (Klaczynski et al., 1997), or be able to decouple the reasoning process from their prior beliefs (Stanovich et al., 2013). Presumably, such complex metacognitive processing requires considerable cognitive effort and contexts where values important to readers are not at stake (Kahan et al., 2012).

Second, as hypothesized, participants typically produced justifications in terms of their personal opinions about the issues, with fewer justifications referring to textual content or other sources of information. In comparison, prior studies have showed that students mainly justify their trust in texts by referring to text content rather than own opinions (e.g., Bråten et 
al., 2011; Rouet et al., 1996; Wiley et al., 2009). One possible reason for the different pattern that we observed may be that the other studies had students rank or rate the trustworthiness of texts included in a set of multiple conflicting texts, with this triggering comparison of contents across texts rather than comparison of content with own opinion. This suggests that readers' personal opinions about an issue may play a larger role in their judgments of trustworthiness when they read one single text rather than a set of conflicting texts on the issue. Moreover, that neither the direction of participants' prior beliefs about the issues, nor the accuracy of their recall, moderated their reliance on personal opinion when justifying their trustworthiness ratings, may be attributable to the fact that participants holding more neutral beliefs about the issues were not included in the analyses. With those included having relatively strong opinions supporting or opposing serious health risks, then, their opinions seemed to become the main basis of their evaluations regardless of their direction (i.e., supposing vs. opposing) and whether the conclusions were correctly or incorrectly recalled.

Third, as we also hypothesized, participants who correctly recalled text conclusions even when those conclusions were inconsistent with their prior beliefs about the issues outperformed participants whose incorrect recall was consistent with their prior beliefs on measures of cognitive reflection and reported use of critical reading strategies. This finding suggests that quite small increases in the ability to suppress the tendency to respond with the first idea that comes to mind and reflect on alternatives may make a difference for the recall of belief-inconsistent information. One possibility is that readers who do not recall text conclusions at odds with their prior beliefs simply do not note a contradiction between their own beliefs and those conclusions due to shallow processing of the text (Petty \& Wegener, 1999), with deeper processing involving cognitive reflection and critical reading strategies needed to note and remember essential text information incongruent with prior beliefs. 
The hypothesis that more participants would recall belief-consistent than beliefinconsistent conclusions was not confirmed, however. While we grounded this hypothesis in meta-analytic work by Roberts (1985) and Stangor and McMillan (1992), suggesting that a delay between reading and recall would increase the probability that readers recall beliefconsistent messages, there may be several reasons why prior topic beliefs were not associated with the recall of belief-consistent or belief-inconsistent conclusions in the present study. For example, despite the inserted problem-solving task, the time interval between reading and recall may have been too short to produce the expected belief-biased recall effect, with the majority of the participants seemingly not drawing on their prior beliefs in reconstructing conclusions from long-term memory but, rather, relying on their immediate memory for the text conclusions. Another possibility is that belief-inconsistent messages influenced participants' memory representations due to their perceived uniqueness, as predicted by "the schema-pointer plus tag model" of Woll and Graesser (1982), with this uniqueness effect neutralizing the consistency effect in this study. Further research is therefore needed to clarify belief bias in readers' recall of socio-scientific information, with such research, for example, systematically varying the time interval between reading and recall as well as the uniqueness of the belief-inconsistent information.

The findings that prior topic beliefs seem to play an important role for readers' trust and mistrust of information they recall from texts on socio-scientific issues and that they may rely more on their personal opinions than on text content or features of the sources when making those judgments are not trivial. As indicated in the introduction, such biased evaluation of socio-scientific information may, in fact, have fatal consequences, for example in the context of important health issues. In school, students' encounters with new, contradictory information are central to knowledge acquisition in science (Chinn \& Brewer, 1993), and belief-biased evaluation may, therefore, represent a major obstacle to learning. 
Both in and out of school, then, readers need to learn how to negotiate belief-inconsistent information in an adaptive way to facilitate learning and deal more rationally with the wealth of complex socio-scientific issues encountered in information-rich societies. Because more critical information processing may be required to decrease belief bias, motivating individuals to process contradictory information more deeply by employing effortful reading strategies has been suggested as one viable educational route (e.g., Chinn \& Brewer, 1993). A caveat is, however, that readers observed to process belief-inconsistent information more deeply may intentionally try to refute that information rather than understand the issue more completely (Klaczynski et al., 1997; Molden \& Higgins, 2005). Additionally, readers therefore may need to be both consciously aware of their prior beliefs and able to judge new information according to other criteria than belief consistency. In support of this view, Stanovich et al. (2013) facilitated less biased processing by explicitly instructing readers to decouple from prior beliefs while working on a reasoning task. Also, instructing readers to make accurate judgments and prepare to discuss the reasons for their evaluations have been found to facilitate more balanced and integrated comprehension of controversial issues (Molden \& Higgins, 2005). Given that our findings suggest that prior beliefs about controversial socioscientific issues may play important roles for how students deal with belief-inconsistent information concerning those issues, much further research is needed in educational settings to clarify how students may be helped to process such information more deeply, at the same time trying to overcome their prior beliefs in achieving a more balanced and integrated view.

Our study does not come without limitations. First, participants' engagement in the issues presumably affected their processing and evaluation of the text messages, with information high in personal relevance and in conflict with individuals' values likely to elicit stronger efforts to achieve belief consistency (Kahan et al., 2012; Kruglanski \& Shteynberg, 2012). However, while the strength of participants' prior beliefs might indicate their level of 
engagement in the current study, no direct measures of personal relevance or values were applied. Moreover, while our measures of cognitive reflection and self-reported critical reading of media reports of science might allow some inferences about participants' text processing, this study did not include any online data on how participants actually processed the texts. Preferably, future work on these issues should therefore employ online methodologies such as verbal protocols, eye-tracking, or time on task to more precisely determine how readers process belief-inconsistent versus belief-consistent information.

Despite such limitations, the present study highlights the importance of prior beliefs when students read about controversial socio-scientific issues in popular media. Dealing with belief-inconsistent information may be considered essential parts of schooling as well as decision making in everyday life. Although an impressive research base exists on issues concerning individuals' attitudes and beliefs, less work addresses such issues in educational settings. Hopefully, our contribution may provide an impetus for much further work on how prior topic beliefs may bias students' text-based learning and on the preventive instructional measures that can be taken to offset their potentially detrimental effects.

\section{References}

Abelson, R.P. (1979). Differences between belief and knowledge systems. Cognitive Science, 3, 355-366, doi:10.1207/s15516709cog0304_4

Andiliou, A., Ramsay, C.M., Murphy, P.K., \& Fast, J. (2012). Weighing opposing positions: Examining the effects of intratexual persuasive messages on students' knowledge and beliefs. Contemporary Educational Psychology, 37, 113-127, doi:10.1016/j.cedpsych.2011.10.001

Bråten, I., Ferguson, L.E., Strømsø, H.I., \& Anmarkrud, Ø. (2013). Justification beliefs and 
multiple-documents comprehension. European Journal of Psychology of Education, 28, 879-902, doi:10.1007/s10212-012-0145-2

Bråten, I., Strømsø, H.I., \& Salmerón, L. (2011). Trust and mistrust when students read multiple information sources about climate change. Learning and Instruction, 21, 180192, doi:10.1016/j.learninstruc.2010.02.002

Chinn, C.A., \& Brewer, W.F. (1993). The role of anomalous data in knowledge acquisition: A theoretical framework and implications for science instruction. Review of Educational Research, 63, 1-49, doi:10.3102/00346543063001001

Field, A. (2010). Discovering statistics using SPSS (3rd ed.). Los Angeles: Sage.

Frederick, S. (2005). Cognitive reflection and decision making. Journal of Economic Perspectives, 19, 25-42, doi:10.1257/089533005775196732

Gawronski, B., \& Strack, F. (2012). Cognitive consistency as a basic principle of social information processing. In B. Gawronski \& F. Strack (Eds.), Cognitive consistency: A fundamental principle in social cognition (pp. 1-16). New York: Guilford.

Kahan, D.M., Peters, E., Wittlin, M., Slovic, P., Ouellette, L.L., Braman, D., \& Mandel, G. (2012). The polarizing impact of science literacy and numeracy on perceived climate change risks. Nature Climate Change, 2, 732-735, doi:10.1038/nclimate1547

Kardash, C.M., \& Scholes, R.J. (1996). Effects of preexisting beliefs, epistemological beliefs, and need for cognition on interpretation of controversial issues. Journal of Educational Psychology, 88, 260-271, doi:10.1037/0022-0663.88.2.260

Klaczynski, P.A., Gordon, D.H., \& Fauth, J. (1997). Goal-oriented critical reasoning and individual differences in critical reasoning biases. Journal of Educational Psychology, 89, 470-485, doi:10.1037/0022-0663.89.3.470

Kruglanski, A.W., \& Shteynberg, G. (2012). Cognitive consistency as means to an end: How 
subjective logic affords knowledge. In B. Gawronski \& F. Strack (Eds.), Cognitive consistency: A fundamental principle in social cognition (pp. 245-264). New York: Guilford.

Lord, C.G., Ross, L., \& Lepper, M.R. (1979). Biased assimilation and attitude polarization: The effects of prior theories on subsequently considered evidence. Journal of Personality and Social Psychology, 37, 2098-2109, doi:10.1037/00223514.37.11.2098

Maier, J., \& Richter, T. (2013). Text-belief consistency effects in the comprehension of multiple texts with conflicting information. Cognition and Instruction, 31, 151-175, doi:10.1080/07370008.2013.769997

McCrudden, M.T., \& Sparks, P.C. (2014). Exploring the effect of task instruction on topic beliefs and topic belief justification: A mixed methods study. Contemporary Educational Psychology, 39, 1-11, doi:10.1016/j.cedpsych.2013.10.001

Molden, D.C., \& Higgins, E.T. (2005). Motivated thinking. In K. J. Holyoak \& R. G. Morrison (Eds.), The Cambridge handbook of thinking and reasoning (pp. 295-320). New York: Cambridge University Press.

Murphy, P.K., \& Alexander, P.A. (2004). Persuasion as a dynamic, multidimensional process: An investigation of individual and intraindividual differences. American Educational Research Journal, 41, 337-363, doi:10.3102/00028312041002301

Murphy, P.K., \& Mason, L. (2006). Changing knowledge and beliefs. In P.A. Alexander \& P.H. Winne (Eds.), Handbook of educational psychology (2nd ed., pp. 305-324). Mahwah, NJ: Erlbaum.

Nisbet, M.C., \& Mooney, C. (2007). Framing science. Science, 316, 56, doi:10.1126/science. 1142030

Norwegian Post and Telecommunications Authority (2013). Befolkningens bruk av 
elektroniske kommunikasjonstjenester [The population's use of electronic communications]. Oslo: NPT.

Petty, R.E., \& Wegener, D.T. (1999). The Elaboration Likelihood Model: Current status and controversies. In S. Chaiken \& Y. Trope (Eds.), Dual-process theories in social psychology (pp. 41-72). New York: Guilford.

Pichert, J.W., \& Anderson, R.C. (1977). Taking different perspectives on a story. Journal of Educational Psychology, 69, 309-315, doi:10.1037/0022-0663.69.4.309

Pintrich, P.R., Smith, D.A.F., Garcia, T., \& McKeachie, W.J. (1993). Reliability and predictive validity of the Motivated Strategies for Learning Questionnaire (MSLQ). Educational and Psychological Measurement, 53, 801-813, doi:10.1177/0013164493053003024

Roberts, J.V. (1985). The attitude-memory relationship after 40 years: A meta-analysis of the literature. Basic and Applied Social Psychology, 6, 221-241, doi:10.1207/s15324834basp0603_3

Rouet, J.-F., Britt, M.A., Mason, R.A., \& Perfetti, C.A. (1996). Using multiple sources of evidence to reason about history. Journal of Educational Psychology, 88, 478-493, doi:10.1037/0022-0663.88.3.478

Stangor, C., \& McMillan, D. (1992). Memory for expectancy-congruent and expectancyincongruent information: A review of the social and social developmental literatures. Psychological Bulletin, 111, 42-61, doi:10.1037/0033-2909.111.1.42

Stanovich, K.E., West, R.F., \& Toplak, M.E. (2013). Myside bias, rational thinking, and intelligence. Current Directions in Psychological Science, 22, 259-264, doi:10.1177/0963721413480174

Taber, C.S., \& Lodge, M. (2006). Motivated skepticism in the evaluation of political beliefs. 
American Journal of Political Science, 50, 755-769, doi:10.1111/j.15405907.2006.00214.x

Toplak, M.E., West, R., \& Stanovich, K.E. (2011). The Cognitive Reflection Test as a predictor of performance on heuristics- and biases tasks. Memory \& Cognition, 39, 1275-1289, doi:10.3758/s13421-011-0104-1

Wiley, J. (2005). A fair and balanced look at the news: What affects memory for controversial arguments? Journal of Memory and Language, 53, 95-109, doi:10.1016/j.jml.2005.02.001

Wiley, J., Goldman, S.R., Graesser, A.C., Sanchez, C.A., Ash, I.K. \& Hemmerich, J. (2009). Source evaluation, comprehension, and learning in Internet science inquiry tasks. American Educational Research Journal, 46, 1060-1106, doi:10.3102/0002831209333183

Woll, S., \& Graesser, A. (1982). Memory discrimination for information typical or atypical of person schemata. Social Cognition, 1, 287-310, doi:10.1521/soco.1982.1.4.287 
Table 1

Descriptive Statistics for the Measured Variables for the Entire Sample

\begin{tabular}{lccc}
\hline Variable & $M$ & $S D$ & Skewness \\
\hline Topic beliefs - Aspartame & 6.42 & 2.55 & -.50 \\
Topic beliefs - Cell phone & 5.60 & 2.74 & -.11 \\
Self-reported knowledge - Aspartame & 4.11 & 2.12 & .60 \\
Self-reported knowledge - Cell phone & 4.46 & 1.90 & .42 \\
Cognitive reflection (CRT) & .29 & .33 & .86 \\
Critical reading (CROMROSS) & 3.04 & .90 & .22 \\
Trust in conclusion - Aspartame & 3.05 & 1.02 & -.47 \\
Trust in conclusion - Cell phone use & 3.14 & .98 & -.35 \\
\hline
\end{tabular}


Table 2

Number of Participants in the Two Belief Groups Recalling Text-Consistent and Text-Inconsistent Conclusions from Each Text

\begin{tabular}{|c|c|c|c|c|}
\hline & \multicolumn{2}{|c|}{ Recall of conclusion - aspartame } & \multicolumn{2}{|c|}{ Recall of conclusion - cell phone } \\
\hline & $\begin{array}{c}\text { Text consistent } \\
\text { (correct) }\end{array}$ & $\begin{array}{c}\text { Text inconsistent } \\
\text { (incorrect) }\end{array}$ & $\begin{array}{l}\text { Text consistent } \\
\text { (correct) }\end{array}$ & $\begin{array}{c}\text { Text inconsistent } \\
\text { (incorrect) }\end{array}$ \\
\hline \multicolumn{5}{|l|}{ Topic beliefs } \\
\hline Text consistent & 24 & 21 & 54 & 14 \\
\hline
\end{tabular}


Table 3

Frequencies and Percentages of Justifications

\begin{tabular}{lcc}
\hline Justification by & Aspartame (\%) & Cell phone (\%) \\
\hline Content & $37(18.1)$ & $49(23.2)$ \\
Main source & $2(1.0)$ & $6(2.8)$ \\
Embedded source & $7(3.5)$ & $7(3.3)$ \\
Other source & $38(18.6)$ & $47(22.3)$ \\
Personal opinion & $120(58.8)$ & $102(48.4)$ \\
\hline Total & $204(100)$ & $211(100)$ \\
\hline
\end{tabular}




\section{Figure Captions}

Figure 1. Trust in text-consistent and text-inconsistent recalled aspartame conclusions by nature of beliefs. Error bars represent standard errors.

Figure 2. Trust in text-consistent and text-inconsistent recalled cell phone conclusions by nature of beliefs. Error bars represent standard errors. 


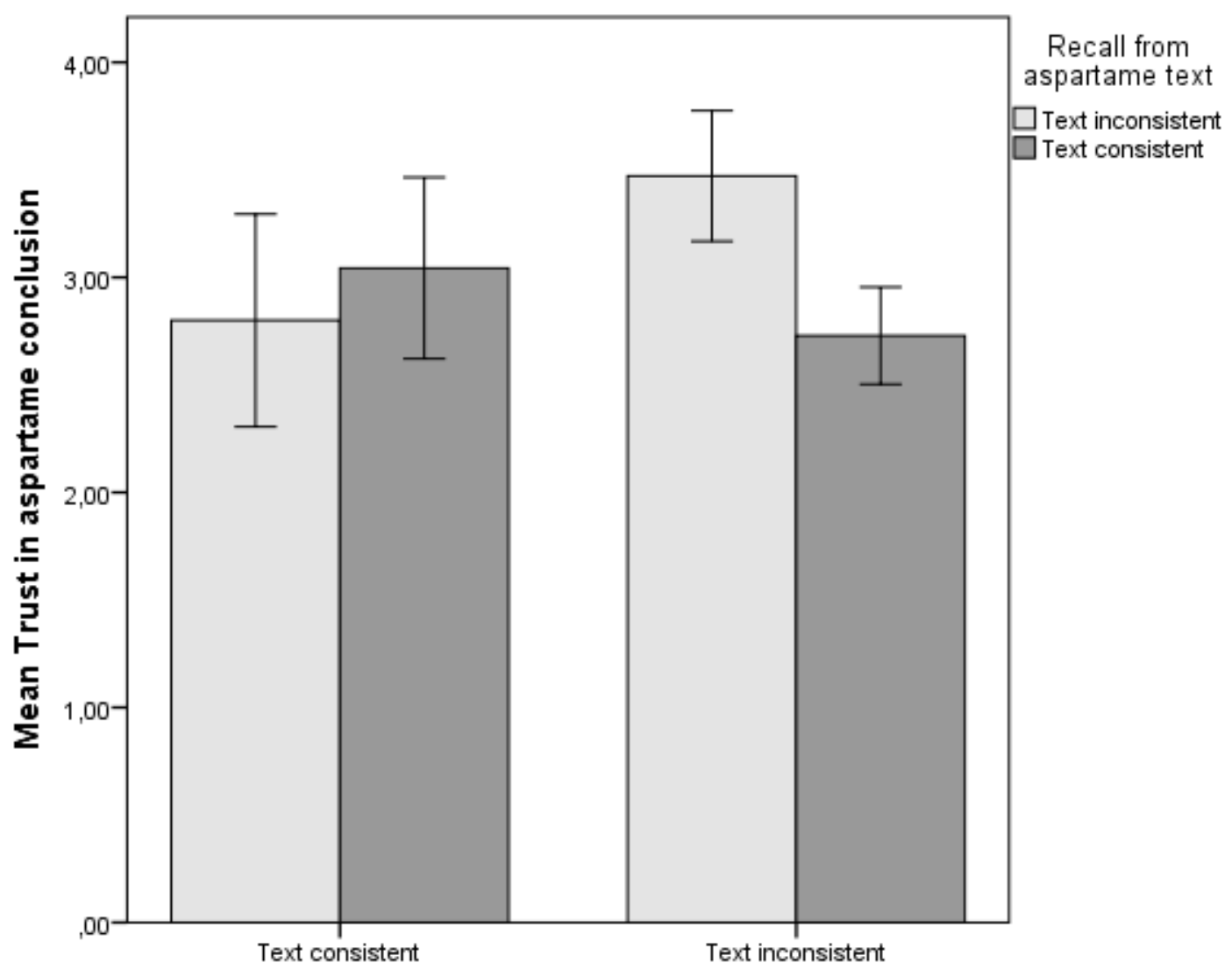

Prior beliefs aspartame

Figure 1 


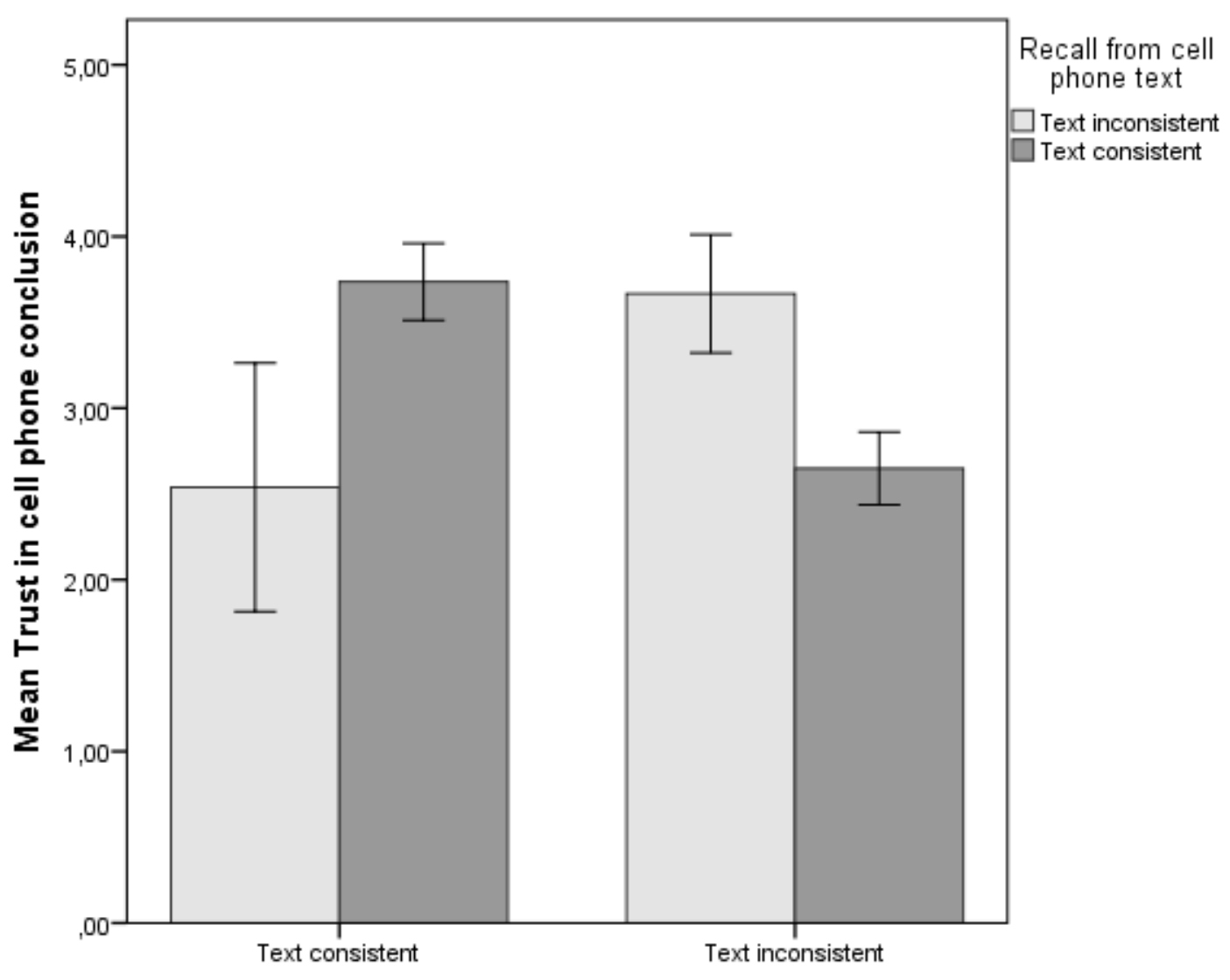

Prior beliefs cell phone

Figure 2 